\title{
FLUXOS DE PRODUTOS E SUBPRODUTOS DE VIDROS NA CADEIA DA INDÚSTRIADE VIDROS: UM ESTUDO DE CASO
}

\author{
FLOWS OF PRODUCTS AND SUBPRODUCTS IN GLASS INDUSTRY CHAIN: A CASE STUDY \\ DOI: http://dx.doi.org/10.12712/rpca.v5i1.17
}

\author{
Anderson da Silva Nascimento \\ Universidade Federal do Rio de Janeiro \\ Natália Gonçalves Pires do Vale \\ Universidade Federal do Rio de Janeiro \\ Tatiana Maria Bernardo da Silva \\ Pontifícia Universidade Católica do Rio de Janeiro
}

\section{RESUMO}

0 vidro é um produto/insumo que se encaixa em um programa de logística reversa. Seu processo de reciclagem oferece uma redução significativa no consumo energético de produção, e a redução do volume de lixo em aterros sanitários. Um material, que possui até maior potencial de reciclagem que as garrafas PET, não recebe a mesma atenção dispensada a este. Este trabalho analisa a estrutura de logística reversa presente na comercialização de vidros. Para isso, entrevistas com todos os agentes do processo de reaproveitamento do material. Foram confrontadas e analisadas as declarações desses agentes com o objetivo de observar como o processo ocorre. Notou-se que o processo de reaproveitamento do vidro poderia mesmo ter a sua definição como um processo de logística reversa questionada, já que a sua existência deve-se à iniciativa de autônomos e por não haver uma organização que se responsabilize pela coordenação deste processo.

Palavras-chave: Logística reversa. Vidro. Reciclagem.

\begin{abstract}
Glass is a product/input that fits in a reverse logistics program. Its recycling process offers a significant reduction in energy needed to production, and reducing the volume of waste in landfills. A material that has even greater potential for recycling than PET bottles that do not receive the same attention to this. This paper analyzes the structure of reverse logistics in the marketing of this glass. For this, interviews with all stakeholders in the process of reusing materials. Were compared and analyzed the statements of these agents in order to observe how the process occurs. It was noted that the process of reusing the glass could even have its definition as a process of reverse logistics questioned since its existence is due to the autonomous initiative and there is no organization that is responsible for coordinating this process.
\end{abstract}

Keywords: Reverse logistics. Glass. Recycling. 


\section{INTRODUÇÃO}

O vidro é um produto/insumo que se encaixa perfeitamente em um programa de logística reversa. É um material não-poroso que resiste a temperaturas de até $150^{\circ} \mathrm{C}$ (vidro comum) sem perda de suas propriedades físicas e químicas. É totalmente reciclável e não ocorre perda de material durante o processo de fusão, ou seja, para cada tonelada de caco de vidro limpo, obtém-se uma tonelada de vidro novo e por volta de 1,2 toneladas de matéria prima deixa de ser consumida (ZEVIZCOVAS, 2008).

Seu processo de reciclagem consiste na adição de cacos devidamente limpos e separados à nova quantidade de matéria-prima, o que reduz o tempo necessário para a fusão e, por conseqüência, uma redução significativa no consumo energético de produção. Em cada $10 \%$ de caco adicional que é introduzido num forno, economiza-se de 2,5 a 3 \% no consumo de energia (CESAR et al, 2004).

Outro grande benefício é a redução do volume de lixo em aterros sanitários, uma preocupação crescente com o aumento da produção de dejetos e a falta de local apropriado para comportá-los.

Isto pode ser comprovado pela pesquisa "A indústria e a questão tecnológica", realizada em 2001 pela Confederação Nacional da Indústria (CNI), Serviço Brasileiro de Apoio às Micro e Pequenas Empresas (SEBRAE), Banco Nacional de Desenvolvimento Econômico e Social (BNDES) e Financiadora de Estudos e Projetos (FINEP) que revela que mais de $50 \%$ de empresas pesquisadas realizam investimentos ambientais, sendo mais de $90 \%$ nas grandes e $35 \%$ nas microempresas. Sendo que $85 \%$ destas não adotaram práticas de gestão ambiental somente em função da legislação, mas principalmente, por aliar a gestão ambiental ao aumento de competitividade e melhorar a imagem perante a sociedade. A gestão ambiental é a resposta natural das empresas ao novo cliente, o "consumidor verde" e "ecologicamente correto".

Mesmo com tantos benefícios a favor da reciclagem do vidro, não é isto que acontece na prática. Um material, que possui até maior potencial de reciclagem que as garrafas PET, pois pode ser reciclado infinitas vezes (CESAR et al, 2004), não recebe a mesma atenção dispensada ao primeiro.

Este artigo se propõe a analisar a estrutura de logística reversa presente na comercialização de vidros e entender como essa ocorre.

Para a realização desta pesquisa foram feitas entrevistas com os agentes do processo e reaproveitamento do material, que são: os clientes (a têmpera e as duas vidraçarias); os transportadores (caminhoneiros autônomos, que nesta pesquisa foi representado por um integrante deste grupo); as recicladoras (a fábrica de vidro e a fábrica de esferas de vidro).

Seção I.1 Na parte de análise dos dados foram confrontadas e analisadas as declarações de todos os agentes com o objetivo de observar como o processo ocorre. Neste ponto foi observado que o processo de reaproveitamento do vidro, considerando de forma estrita as definições levantadas, poderia mesmo ter a sua definição como um processo de logística reversa questionada. Devido a sua falta de organização e planejamento e apenas existindo devido à iniciativa de autônomos motivados pelo impulso de oferta e procura destes dejetos e devido à falta de uma empresa que se responsabilize pela coordenação deste processo.

\section{REVISÃO BIBLIOGRÁFICA}

\section{LOGÍSTICA REVERSA}

A logística reversa ou fluxo reverso são estudados desde a década de 70. Todavia, estes estudos ainda não trabalhavam com estes termos, sendo mais comum o uso do termo reciclagem (BRITO \& DEKKER, 2003).

A primeira tentativa de definição para logística reversa aparece em Murphy e Poist (1989), a qual seria "a movimentação de produtos do consumidor em direção ao produtor na cadeia de distribuição", 
conceito que posteriormente também foi apresentado por Pohlen e Farris (1992) e Dowlatshahi (2005). Como se pode perceber, esta não é uma definição satisfatória e precisava ser mais bem detalhada. No entanto, posteriormente, esta necessidade foi atendida através da publicação pelo Council of Logistics Management (CLM) da que é conhecida como a primeira definição de Logística Reversa (STOCK, 1992, apud BRITO \& DEKKER, 2003, p. 2):

...the term often used to refer to the role of logistics in recycling, waste disposal, and management of hazardous materials; a broader perspective includes all relating to logistics activities carried out in source reduction, recycling, substitution, reuse of materials and disposal.

Apesar de mais completa, esta definição ainda não possuía um enfoque empresarial e hoje poderia ser mais associada ao que é denominado Logística Verde (BYRNE \& DEEB, 1993; CARTER \& ELLRAM, 1998; WU \& DUNN, 1995), devido a sua abordagem ambiental. Em Stock (1998), apud Gonçalves e Marins (2006), esta definição tem seus limites ampliados:

...sob a perspectiva logística do negócio, se refere ao papel da Logística no retorno de produtos, na redução de uso de matéria-prima virgem, no uso da reciclagem, na substituição de materiais, no reuso de materiais, na disposição de resíduos, no recondicionamento, no reparo e no remanufaturamento de produtos; e. Do ponto de vista de engenharia, se refere ao gerenciamento dos processos acima e é como um modelo sistemático de negócios que aplica as melhores metodologias de engenharia e administração conhecidas para fechar, com lucratividade, o ciclo em uma Cadeia de Suprimentos (p.2).

Hoje, segundo a Reverse Logistics Executive Council - RLEC (http://www.rlec.org/glossary.html), a logística reversa é "The process of planning, implementing, and controlling the efficient, cost effective flow of raw materials, in-process inventory, finished goods and related information from the point of consumption to the point of origin for the purpose of recapturing value or proper disposal".

Ainda é apresentado por esta organização um quadro comparativo entre a Logística Tradicional e a Logística Reversa (Quadro 1), onde são apontadas as características de cadauma.

Também sobre a definição dada pela RLEC, é interessante notar que a organização também recupera o conceito inicial de logística reversa como o movimento de bens do consumidor final para seu fornecedor, assim como todos os outros de algum modo também fizeram.

Quadro 1: Quadro Comparativo entre as características de logística Reversa e Tradicional

\begin{tabular}{|l|l|}
\hline Diferenças entre a Logística tradicional e a Logística Reversa \\
\hline Logística Tradicional & Logística Reversa \\
\hline Previsão relativamente simples & Previsão mais difícil \\
De um para muitos pontos de distribuição & De muitos para um ponto de distribuição \\
Qualidade uniforme do produto & Qualidade não uniforme do produto \\
Embalagem uniforme do produto & Embalagem do produto freqüentemente danificada \\
Destinação clara & Destinação pouco clara \\
Opções de disposição claras & Opçães de disposição pouco claras \\
Preço relativamente uniforme & Precificação dependente de muitos fatores \\
Reconhecida importância da velocidade & Velocidade freqüentemente não considerada uma prioridade \\
Custos de distribuição facilmente visível & Custo direto menos visível \\
Gestão de estoque consistente & Gestão de estoque inconsistente \\
Ciclo de vida do produto gerenciável & Ciclo de vida do produto mais complexo \\
Negociação simples entre as partes & Negociações complicadas por muitos fatores \\
Métodos de marketing bem conhecidos & Marketing complicado por muitos fatores \\
Visibilidade do Processo mais transparente & Visibilidade do Processo menos transparente \\
\hline
\end{tabular}

Fonte: Adaptado de Reverse Logistics Executive Council. 
Lacerda (2002) amplia o conceito de logística reversa, vemos que os materiais não necessariamente precisam retornar para o seu fornecedor para ser reinserido em seu processo de produção, mas também podem ser revendidos se ainda estiverem em condições adequadas de comercialização. Podem ser recondicionados, desde que haja justificativa econômica. Podem ser reciclados se não houver possibilidade de recuperação. Todas estas alternativas geram materiais reaproveitados, que entram de novo no sistema logístico direto. Em último caso, o destino pode ser o seu descarte final (Figura 1).

Figura 1: Atividades Típicas do Processo de Logística Reversa

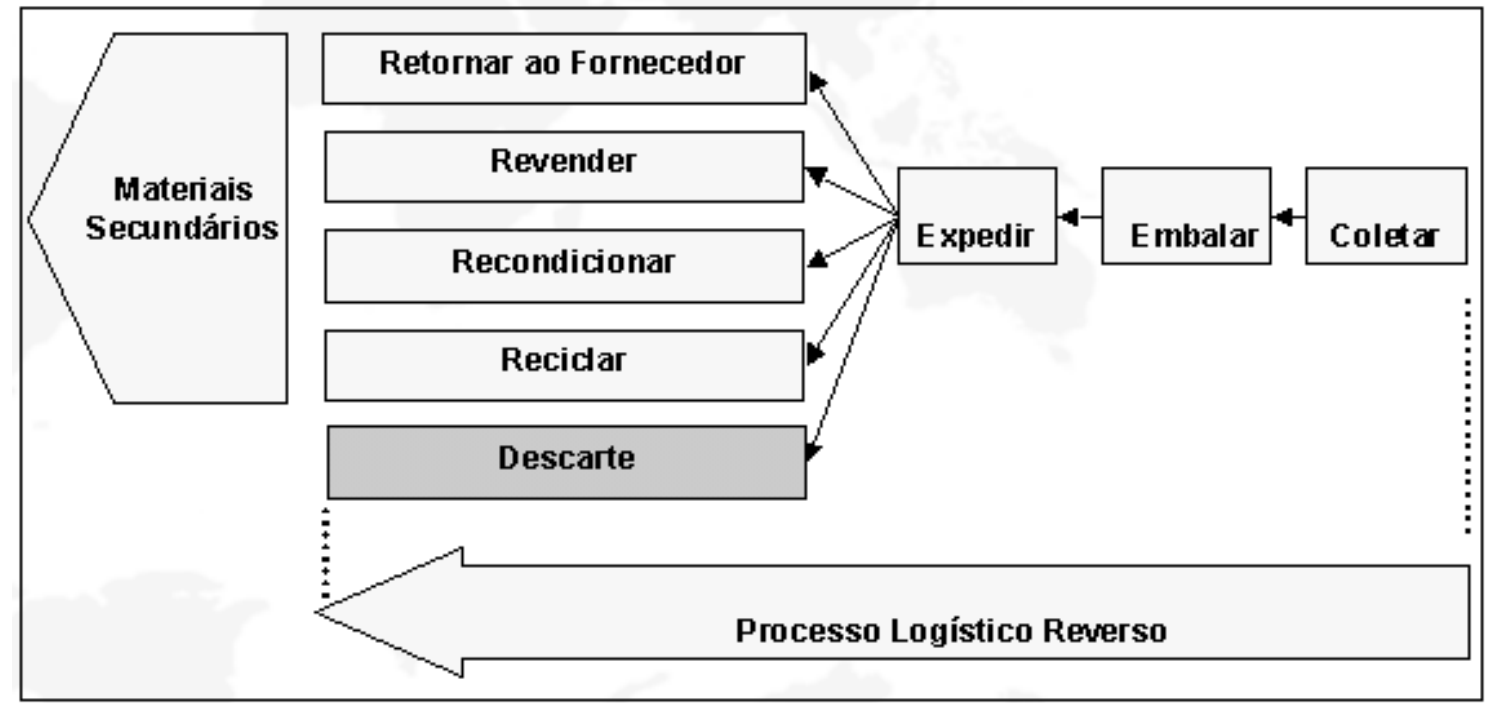

Fonte: ROGERS \& IBBENLEMBKE (1999)

Isto tem uma importante implicação, no momento que observamos que a logística reversa não precisa necessariamente ter um fluxo reverso, ou seja, o material não precisa retornar de um consumidor para um fornecedor, ele pode partir do que seria o consumidor final para o primeiro produtor de outra cadeia logística. Aparentemente, este processo pode parecer incoerente com o termo logística reversa, mas não o é quando observado sob a perspectiva do reaproveitamento do material. Aqui temos o dejeto como matéria-prima de outra cadeia logística.

Ainda assim, este processo será mais bem evidenciado no estudo de caso, pois no processo que será apresentado entre a têmpera e a fabricante de esferas de vidro, a empresa que produz o dejeto não é a mesma que utilizará o produto final do material reaproveitado, ela apenas o prepara para que seja coletado por caminhoneiros autônomos que vendem o material para outra empresa que o utilizará.

Este é um processo diferente do que também é apresentado neste mesmo estudo de caso, entre as vidraçarias e as fábricas de vidro. Este último que se assemelha mais aos processos apresentados em González-Torre e Adenso-Diaz (2006) no reaproveitamento do vidro na Espanha e na Bélgica, e em Gonçalves \& Marins (2006), que apresenta um estudo de caso de uma laminadora de vidros e o processo de reaproveitamento dos dejetos de sua produção. Como será visto no decorrer do texto, mesmo estes dois textos apresentam razoáveis diferenças em seu objeto de estudo.

Ainda em Lacerda (2002) são apresentados os fatores críticos de influência no processo de logística reversa (Quadro 2): 
Quadro 2: Fatores críticos para a eficiência do processo de logística reversa

\begin{tabular}{|c|c|c|}
\hline $\begin{array}{l}\text { Bons } \\
\text { Controles } \\
\text { De Entrada }\end{array}$ & $\begin{array}{l}\text { Processos } \\
\text { Mapeados } \\
\text { E Formalizados }\end{array}$ & $\begin{array}{l}\text { Ciclo de Tempo } \\
\text { Reduzido }\end{array}$ \\
\hline $\begin{array}{l}\text { Sistemas de } \\
\text { Informações } \\
\text { Acurados }\end{array}$ & $\begin{array}{l}\text { Rede } \\
\text { Logística } \\
\text { Planejada }\end{array}$ & $\begin{array}{l}\text { Relações } \\
\text { Colaborativas } \\
\text { Entre Clientes } \\
\text { E Fornecedores }\end{array}$ \\
\hline
\end{tabular}

A observância destes fatores pode ser importante quando se deseja fazer a análise de um processo de logística reversa e identificar as suas falhas. São eles:

Para que um material possa ser reaproveitado é necessário que ele esteja nas condições adequadas e exigidas para a sua entrada em um novo processo de produção. Caso isto não seja feito será perdido um tempo demasiado longo devido a não padronização deste processo, além de ter de por vezes realizar nova separação do material ou mesmo haver danos caso não seja observado que um dejeto inadequado está sendo reintroduzido no processo de produção.

Como dito em Lacerda (2002), "um das maiores dificuldades na logística reversa é que ela é tratada como um processo esporádico, contingencial e não como um processo regular". Este tipo de característica não é apontado no quadro da RLEC, mas como poderá ser observado no estudo de caso, este é um problema que pode resultar em uma maior volatilidade do mercado e ineficiência do processo.

Quanto menor o tempo entre a criação do dejeto e a sua reciclagem, maiores serão os benefícios, como menor custo de armazenagem, criação de caixa mais rápida, etc.

Em um sistema onde uma empresa não faz a coordenação do processo de logística reversa, este tempo de ciclo tende a ser cada vez maior, pois o mercado não será controlado e ficará volúvel as alterações de preço e de estoque dos agentes, o que torna completamente incerto este tempo.

"A capacidade de rastreamento de retornos, medição dos tempos de ciclo, medição do desempenho de fornecedores (avarias nos produtos, por exemplo) permite obter informação crucial para negociação, melhoria de desempenho e identificação de abusos dos consumidores no retorno de produtos" (LACERDA, 2002: p.6).

Instalações centralizadas dedicadas ao recebimento, separação, armazenagem, processamento, embalagem e expedição de materiais retornados podem ser uma boa solução, desde que haja escala suficiente.

Neste tópico o autor trata mais da questão do retorno de produtos defeituosos e do conflito entre fornecedor e varejista sobre de quem é a responsabilidade. No entanto, mesmo em situações de pósconsumo é necessário haver um bom relacionamento entre ambas as partes para que o sistema possa funcionar sem problemas.

Gonçalves e Marins (2006) afirmam que antes de se falar em Logística Reversa deve-sepensar sob três pontos de vista sobre produtos e suas respectivas embalagens: logístico, o ciclo de vida do produto vai além da venda deste, muitas vezes produto tem de voltar ao ponto de origem para serem reparados, reaproveitados ou ter o descarte correto; financeiro, custos logísticos; e, ambiental, impactos do produto ao meio ambiente ao longo de sua vida.

A logística reversa não se trata só da reciclagem e reutilização de material e a reutilização com 
objetivos ambientais. Essa também é pensada quando se trata do pós-venda de produtos com defeitos de fabricação, vendas pela Internet, etc (SILVA \& ROSSI, 2009).

Há tempos se investe em logística, distribuição e marketing visando um aumento no consumo. Porém, a maioria das empresas não tem pensado no fluxo inverso, voltado para a reciclagem (GONÇALVESDIAS \& TEODÓSIO, 2006).

\section{RECICLAGEM DO VIDRO}

Quando se trata de reciclagem de resíduos sólidos, esta depende de fatores como: proximidade das instalações de processamento, custos de estocagem desses resíduos, volume de resíduos, e o custo de transporte destes (VIEIRA \& RICCI, 2008).

O vidro encaixa-se perfeitamente em um programa de logística reversa, como já visto na parte introdutória. A reciclagem do vidro tem como grande atrativo a economia de energia e matéria-prima. A cada quilograma de vidro reciclado substitui 6,6 quilogramas de areia e consome $70 \%$ menos energia do que a utilizada para a fabricação inicial (ASSIS, 2006).

Outro grande benefício é a redução do volume de lixo em aterros sanitários, uma preocupação crescente com o aumento da produção de dejetos e a falta de local apropriado para comportá-los. Como citado por Schenini, Silva e Cardoso (2006), a reciclagem surge como uma alternativa para a solução da questão do lixo das cidades.

Para um país que produz, por dia, 100 mil toneladas de lixo (VIEIRA \& RICCI, 2008). Sendo que boa parte deste lixo é descartada de modo irregular, em terrenos vazios ou lixões. Os programas de reciclagem são essenciais para permitir um prolongamento da vida útil dos aterros sanitários das grandes cidades.

\section{METODOLOGIA}

A estratégia e o tipo de pesquisa a ser adotada irão depender da situação que se apresenta, dos objetivos que se tem, das exigências de tempo e recursos. É nessa ponderação que deve prevalecer o bom senso do pesquisador. É importante considerar (ainda que este seja um exercício tanto complexo) qual o valor da informação que se deseja obter, bem como o grau de precisão desejado (FREITAS \& MOSCAROLA, 2002, p. 7).

O desenvolvimento da pesquisa foi realizado com a utilização de métodos que melhor capturassem as informações almejadas e que tirassem melhor proveito da facilidade de acesso de um dos pesquisadores a uma das empresas estudadas. Assim como dito por Neves (1996), o qual descreve que faz parte da pesquisa qualitativa a obtenção de dados descritivos através de contato direto e interativo do pesquisador com o objeto de estudo. Sendo frequente que o pesquisador procure os fenômenos, segundo a perspectiva dos participantes da situação em estudo para, a partir daí, fazer interpretações sobre os fenômenos. Para o autor, os métodos qualitativos, embora difiram em forma e ênfase, eles trazem como contribuição uma mistura de procedimentos de cunho racional e intuitivo capazes de contribuir para um melhor entendimento dos fenômenos estudados.

Patrício et al. (1999) afirmam que os métodos qualitativos de pesquisa apresentam características próprias que reconhecem a subjetividade nas interações humanas, a diversidade e a complexidade dos fenômenos sociais, o que requer uma gama de possibilidades de métodos que possa dar conta de descrever, interpretar e compreender a realidade, levando em consideração a especificidade e o caráter coletivo do ser humano.

Este artigo trata de um estudo de caso em logística reversa de vidro. 0 estudo de caso é um estudo qualitativo que tem caráter exploratório, sem controle experimental ou de manipulação. Além de ser uma ferramenta útil quando o estudo tem como foco um evento contemporâneo (POZZEBON \& FREITAS, 1998). Segundo Godoy (1995), este tipo de estudo tem como preocupação o estudo do 
ambiente natural, valorizando o contato direto e prolongado do pesquisador com o objeto, ou a situação que está sendo estudada. 0 pesquisador se transforma em instrumento de observação, seleção, análise e interpretação dos dados coletados.

O estudo de caso busca analisar as decisões tomadas, a razão de determinadas atitudes e quais foram os resultados destas. Sendo esclarecidas as causas e resultados do fenômeno dentro do momento e circunstâncias em que essas ocorrem (SEGATTO-MENDES \& MENDES, 2006).

Vieira e Tibola (2005) acreditam que é necessário que um pesquisador veja que nem sempre estruturas bastante formais devem ser utilizadas quando se quer obter informações dos respondentes, porque alguns podem não querer responder sobre um determinado assunto, ou sejam incapazes disso, ou ainda o seu comportamento pode ser influenciado por fatores que eles não têm consciência.

Foram entrevistadas empresas que utilizam o vidro proveniente da logística reversa como matériaprima. A primeira produzindo um novo produto com aquilo que antes seria detrito, no caso micro esferas de vidro. Também possui sua sede no estado do Rio de Janeiro. As outras empresas são produtoras de vidro plano de São Paulo e Rio de Janeiro, que reintroduzem os dejetos em sua linha de produção e os colocam novamente no mesmo fluxo produtivo.

Sobre entrevistas, Gil (2006) expõe que essas são bastante adequadas para saber o que as pessoas pensam, crêem, sentem, desejam, fazem e pretendem fazer. A entrevista é uma técnica flexível, que permite a obtenção de um maior número de respostas, além de permitir que, no contato com o entrevistado, algumas perguntas possam ser adaptadas ou explicadas.

0 tipo de entrevista utilizado na condução da coleta de dados foi entrevista em profundidade. Segundo Aaker, Kumar e Day (2004), entrevistas em profundidade são realizadas frente a frente com o respondente, onde o objetivo da pesquisa é explorado em detalhes. Esses autores ainda informam que há dois tipos básicos de entrevista: não-diretivas, em que o respondente tem a máxima liberdade de resposta, e semi-estruturadas, onde o pesquisador procura cobrir uma lista de assuntos e subáreas. 0 primeiro tipo de entrevista foi utilizado para a condução dessetrabalho.

Considerou-se relevante entrevistar representantes de todos os agentes neste processo, pois representam o começo, o meio e o fim da existência da logística reversa nesta situação. Também foi entrevistado o Sr. X, autônomo, que atua hoje em dia buscando de vidraçaria em vidraçaria o material desperdiçado e transportando-o para as grandes firmas em São Paulo que o transformarão em vidro plano novamente. Neste caso, a entrevista foi feita de forma livre, permitindo que o entrevistado extrapolasse o formato de questionário, imprimindo maior reconhecimento à declaração.

Nas vidraçarias e na têmpera de vidro, os dados foram obtidos por meio de entrevistas pessoais realizadas diretamente com os sócios dos estabelecimentos. Já nas empresas que utilizam a sucata de vidro, as entrevistas ocorreram por meio de correio eletrônico, dado restrições internas, por serem multinacionais e estarem submetidas a diversas normas de suas matrizes.

Deste modo, acreditando que esta seria a melhor forma de conseguir extrair as informações necessárias, utilizou-se de entrevistas semi-estruturadas. As quais foram realizadas de modo informal. A informalidade foi adotada como estratégia para evitar a intimidação dos entrevistados em face de uma situação rígida de uma entrevista acadêmica, o que poderia levar a respostas conservadoras, no sentido, de haver uma tentativa de não dar respostas "incorretas".

Com relação à linguagem utilizada, também se tentou evitar o uso de jargões acadêmicos, tanto para evitar a intimidação do entrevistado, como dito anteriormente, quanto para evitar erros de interpretação. Assim, foi possível desenvolver um bom canal de comunicação e a possibilidade de posteriores confirmações sobre a correção da interpretação das entrevistas.

Desta forma, as informações obtidas foram extremamente relevantes ainda mais pelo fato de que o sócio da têmpera de vidro já havia trabalhado com recolhimento de sobras de vidro como autônomo 
no início de sua vida profissional, enriquecendo ainda mais o estudo.

Deve-se observar que na condução das entrevistas, o entrevistador deve evitar parecer superior ao entrevistado, deixando este à vontade, ser imparcial e ao mesmo tempo pessoal, fazer perguntas de modo informativo, não aceitar respostas monossilábicas, e investigar o entrevistado (MALHOTRA, 2005).

Lima (1999, p.12) destaca que "é importante que os entrevistados compreendam as questões da mesma maneira e que as respostas sejam codificadas sem possibilidade de incerteza". Uma pergunta mal compreendida pode gerar respostas errôneas e que não atendem ao intuito da pesquisa.

Devido à natureza qualitativa do trabalho e da pequena amostra, reconhecemos que este trabalho não poderá ser extrapolado de maneira idêntica para todas as cadeias de empresas que atuam no mercado vidreiro. Isto representa uma limitação do método deste estudo.

\section{ESTUDO DE CASO}

Descrevendo resumidamente, a cadeia de suprimentos do vidro abordada por este trabalho inicia-se na produção de vidros planos, passa pelas vidraçarias e têmperas de vidro, volta por transportadores autônomos ou segue para reciclagem.

A produção de vidros planos possui maior concentração de empresas devido a maior necessidade de capital para entrada na indústria. Devido a este mesmo fato, a concorrência também é reduzida, dadas a característica oligopolista e a dificuldade de ocorrência de novos entrantes.

As vidraçarias e a têmpera de vidro são processadoras de vidro, apenas o beneficiam: moldam, cortam, pintam, jateam e temperam conforme as necessidades de seus clientes. Por já comprarem a chapa de vidro em um dos tamanhos padrão, 3,21/3,60 x 2,00m 3,21/3,60 x 2,20m 3,21/3,60 x 2,40m (linha standard) ou 3,21 x 4,40m 3,21 x 6,00m (linha jumbo) mesmo com o melhor aproveitamento da mesma, ocorrem perdas e quebras no processo de transformação do vidro. Estes dejetos podem tanto ser reutilizados pelas empresas de fabricação de vidro, quanto podem ser reciclados.

Este é o caso da empresa que compra cacos de vidros selecionados nas cores verde e incolor. Através de um processo de moagem, são produzidas micro esferas de vidros de diversos diâmetros. Essas esferas possuem diversas aplicações: desaglomeramento de pigmentos para tintas; corantes; revestimentos têxteis e de papel; moldagem de óculos; produtos farmacêuticos e para agricultura; filtração e cosméticos; transferência de calor; decoração.

A maior parte de sua produção é para a exportação. No Brasil, tem sua maior utilização na produção de tinta para sinalização viária, conferindo à mesma a retrorrefletividade em ocasiões noturnas, quando o foco do farol incide sobre a mesma.

O fluxo do vidro para reutilização ou reciclagem é realizado por autônomos. 0 entrevistado deste grupo, aqui chamado Sr. X, é um autônomo que trabalha recolhendo sucatas de vidro das pequenas empresas, como vidraçarias, lojas de materiais de construção, serralherias e as transporta e vende para as fábricas. Lá serão novamente reutilizadas ou recicladas.

Algo que pôde ser observado foi a ausência de uma estrutura formal de logística reversa de vidro. Não existem pessoas jurídicas envolvidas no processo de recolhimento e transporte para os agentes reutilizadores, fato este que caracteriza a qualidade improvisada desta operação.

Este papel acaba sendo realizado por autônomos que vão de vidraçaria em vidraçaria recolhendo os cacos em seus caminhões próprios.

Geralmente, esse serviço é feito de graça devido ao fato de representar uma relação ganha-ganha entre ambos: a vidraçaria descarta seus dejetos em conformidade com aspectos ambientais e o autônomo ganha ao levar o material até alguma das fábricas de vidro que compram este material, entre elas 
Guardian, Saint Gobain (estas reciclam o material transformando-os novamente em vidro plano), localizadas no Rio de Janeiro e em São Paulo, respectivamente, recebendo o suficiente para lucrar e pagar o frete até outro estado.

O cenário encontra-se desta forma, estabilizado, há dois anos. 0 preço pago pela sucata é arbitrado pelas fábricas de acordo com as condições do vidro apresentado, se estão limpos, separados por cor. E, principalmente, são definidos segundo as necessidades da fábrica, ou seja, se estão com estoques baixos de sucata, necessitando da mesma para incluir na produção a fim de melhorar a composição da mistura a ser derretida, ou se há muita oferta e seus estoques estão altos. Percebe-se neste ponto, o poder de barganha que a fábrica possui ao impor o preço a ser pago pela tonelada de sucata aos autônomos conforme suas necessidades internas.

Entretanto, pode existir a cobrança deste serviço para as vidraçarias, caso o preço da sucata esteja desvalorizado e não seja vantajoso realizar a viagem até São Paulo. Nesta situação, corre o risco de o autônomo não respeitar as condições de preservação ao meio ambiente, realizando o despejo em rios ou lixões, contaminando o meio ambiente com esse material que não é biodegradável.

Outro cenário também ocorre: o preço da sucata Estar elevado. Desta maneira, aumenta a quantidade de autônomos assediando as vidraçarias. Para garantir ser o escolhido pela retirada da sucata, ele pagam alguma quantia, extremamente volátil, às mesmas. Na entrevista com o Sr. $\mathrm{X}$, tomamos conhecimento desta volatilidade. Ele explica como o mecanismo funciona: conforme os preços pagos nas fábricas aumentam, mais profissionais do ramo de frete se deslocam para o específico da sucata de vidro, o que faz aumentar a concorrência e a escassez de material a sertransportado.

Deve-se ressaltar que a relação autônomo-vidraçarias é inteiramente informal, não existindo nada que garanta uma freqüência de serviço entre ambos. Ainda assim, existem autônomos que trabalham há anos com as mesmas vidraçarias, estabelecendo uma relação concreta, entretanto sempre informal.

Outro ponto a frisar é que a vidraçaria, a priori, não possui qualquer conhecimento sobre o preço praticado pela fábrica sobre os cacos de vidro para os autônomos. 0 preço sobre a tonelada de sucata é estipulado pelas empresas que vão derretê-lo novamente, geralmente as grandes fábricas em São Paulo que possuem fornos capazes para tal. O valor pago aos autônomos não é conhecido pelos vidraceiros, conforme constatado na entrevista com a proprietária de uma das vidraçarias supracitadas.

Outro destino dado às sucatas de vidro revelado nas entrevistas com as vidraçarias foi o fato de que algumas destas, por conta própria e pelo fato de os autônomos não as atenderem, já que estão fora da rota dos mesmos, optam por elas mesmas eliminarem os detritos. Por acharem mais prático, acabam se livrando dos cacos de qualquer jeito, jogando em lixo em locais inadequados, mas não se conscientizam de que estão poluindo o próprio local onde vivem, pois geralmente escolhem um lugar próximo pra descartarem.

A maneira mais comum é jogar em rios, valões ou lixões, estes na maioria das vezes são clandestinos, o que prejudica ainda mais o meio ambiente.

A têmpera de vidros é a principal fornecedora de matéria-prima para a empresa de fabricação de micro esferas de vidros, chegando a ser responsável por $90 \%$ do total (os $10 \%$ restantes são preenchidos por têmperas concorrentes do estado do Rio de Janeiro). A primeira trabalha com vidros de todas as qualidades e seu desperdício está dividido conforme o gráfico que segue: 
Grafico 1: Desperdício em porcentagem por categoria

\section{Desperdício em Porcentagem por Categoria}

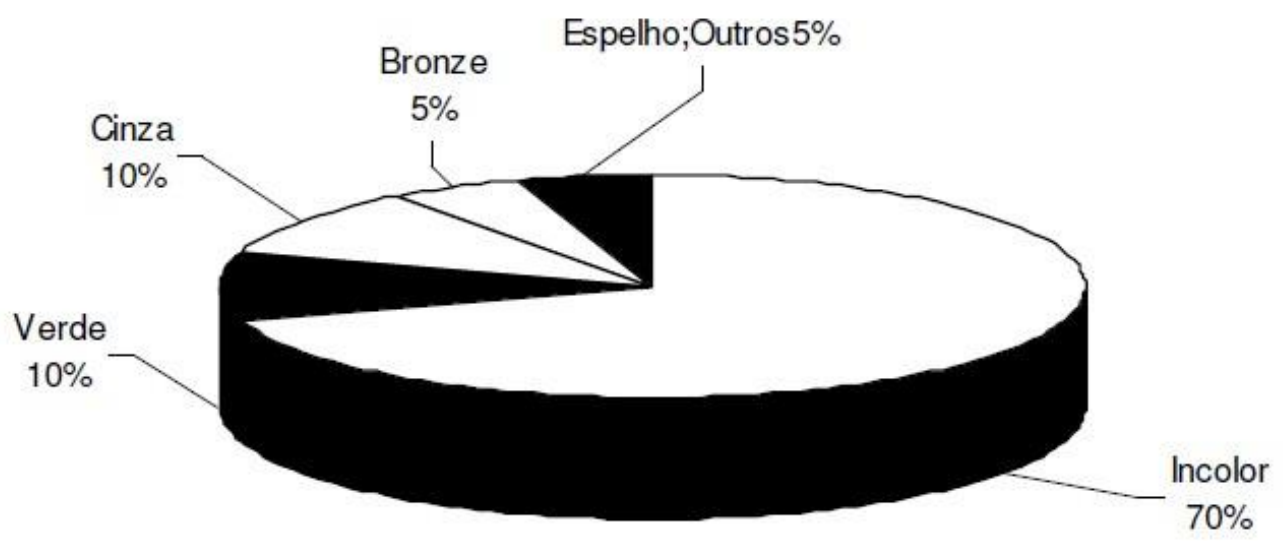

Outros: Vidros muito espessos.

Fonte: Dados da empresa.

Na têmpera de vidros percebe-se uma relação melhor estruturada que a das vidraçarias com os autônomos, finalizando maior proveito da sucata. A primeira lucra ao fornecer a sucata, ainda que possua o custo de separar as qualidades de vidro, armazenagem, fatos estes que não acontecem nas vidraçarias.

Para a empresa produtora de micro esferas, são necessários cacos de vidro incolor e verde. Assim, os vidros de qualidades restantes são retirados também por autônomos que se encarregam de levar às fábricas em São Paulo. Conforme descrito anteriormente, o cenário encontra-se estabilizado e nada é pago ou ofertado pelo autônomo.

Para o diretor dessa empresa que se utiliza dessa sucata, a relação é extremamente favorável, pois $90 \%$ da matéria-prima é a sucata fornecida pela têmpera de vidro. 0 processo mostra-se prático, rápido, pois estão próximos fisicamente um do outro e a qualidade é bem elevada, o que gera uma cadeia de produtos de boa qualidade uma vez que esta é a matéria prima do primeiro. E os benefícios ao meio ambiente também são potencializados - ao utilizarem o que antes seria dejeto, o destinam a um o mais ecologicamente correto: um o novo produto.

Outras empresas descartam pelos garis mesmo, dando uma gorjeta extra, ou pagam carroceiros que buscam o vidro e, com caminhões próprios os vendem a recicladoras de vidros que fazem bolinhas de gude, copos, etc. Ainda existe uma pequena parte dos dejetos que é vendida para artesãos que fazem lembrancinhas de igreja etc.

A fábrica de vidro não consegue usar esse vidro trazido pelos carreteiros pois ocorre muita mistura entre os vidros: importados, de outras fábricas (que possuem processos e origem de matérias primas distintas), de diversas qualidades...etc. Eles apenas reciclam os vidros que brados dentro de sua própria linha de produção.

\section{CONCLUSÕES}

Diferente do que ocorre na mentalidade deste mercado, a reciclagem do vidro tem potencial para ser bem melhor aproveitada, devido a sua capacidade de reutilização integral e dos benefícios quanto a 
redução nos custos da produção de novos vidros e do provimento de um fim adequado para os dejetos, que se descartados sem os devidos cuidados irão poluir o meio ambiente.

Ainda assim, o vidro possui uma taxa de reaproveitamento relativamente pequena, quando comparado a outros produtos que possuem maior taxa de reciclagem, como as latinhas de alumínio. Podemos afirmar que isto se deve, em grande parte, a falta de uma estrutura formal e bem coordenada deste processo, o que resulta em oscilações constantes do mercado, o que por sua vez inibe o seu desenvolvimento.

Apesar de haver um fluxo reverso de materiais, podemos mesmo questionar se o processo apresentado no caso pode ser definido como um processo de logística reversa. Uma vez que quando observada, por exemplo, a definição de logística reversa pela RLEC, não notamos de forma clara dentro do processo apresentado no caso, as mesmas características que estão presentes na definição. Aqui nos referimos a características, como planejamento, implementação e controle. No estudo de caso pudemos perceber que estas características são inexistentes e o processo de logística reversa é realizado apenas pela livre iniciativa de agentes autônomos (e por vezes esporádicos), os quais são motivados pela variação entre a oferta e a procura dos dejetos.

Um pouco diferente é o processo realizado entre a têmpera e a empresa de fabricação de esferas de vidro. Nesta relação, existe alguma constância no fornecimento, assim como um melhor controle dos dejetos a serem transportados, pois uma maior dependência da segunda pela matéria-prima fornecida pela primeira.

Esta relação também pode ser interessante de ser estudada um pouco mais a fundo, uma vez que ela pode nos fazer questionar qual seria a verdadeira definição deste processo que não possui um fluxo reverso. Apesar de haver um reaproveitamento de materiais pósconsumo, este não retorna para o fornecedor ou qualquer outro agente anterior da cadeia produtiva, mas sim, ele vai para o produtor de um produto diferente que percorrerá uma cadeia logística diferente.

Por fim, é interessante observar que apesar da logística reversa do vidro entre as empresas citadas no caso ser feito de forma espontânea por agentes autônomos e, por isso mesmo, com alta volatilidade, sem constância. Ainda assim, podemos observar que a livre iniciativa destes agentes contribui para o reaproveitamento de grande parte do dejeto, que de outro modo, estaria poluindo o meio ambiente, mas que estão criando e explorando (mesmo que de forma ineficiente) uma nova oportunidade de negócio, que a priori deveria ser observada pelas empresas envolvidas e interessadas em dar um fim adequado aos seus dejetos e desenvolver uma vantagem competitiva, que seria adquirida graças ao fortalecimento da parceria entre fornecedores e clientes, e redução de custos no processo produtivo do fornecedor e aumentando a receita do cliente com um material que não lhe é maisútil.

Um bom exemplo de importante vantagem que pode ser apresentado é o dado em HIPPEL (1988), o qual mostra como em muitos setores a principal fonte de inovação é o usuário/cliente, que costuma adaptar os produtos que recebe adicionando melhorias ou mesmo criando produtos inteiramente novos. No entanto, isto somente é possível de ocorrer quando existe um fluxo de informações inverso ao fluxo normal dos produtos. Sendo que para que tal fluxo se estabeleça é necessária a existência de uma relação mais próxima entre estes atores. 0 que pode ser propiciado, também, por uma rede bem estruturada de logística reversa.

No entanto, a necessidade de inovar somente existe, como mostrado em SCHUMPETER (1934), quando o empreendedor se encontra em um mercado com alto ou médio nível de concorrência, no qual é necessário inovar para que se possa almejar um aumento da parcela de mercado e/ou maior lucratividade, ou o concorrente poderá fazer isto primeiro e adquirir uma vantagem. Este, que não é o caso da indústria vidreira, como pode ser visto em Moran(2008).

Sendo assim, um pesquisador com maior conhecimento sobre o assunto, poderá observar o conceito da "mão invisível" de Adam Smith neste caso e verificar que apesar da não operação deste mercado da forma mais eficiente, ainda assim, foi o responsável pala criação e o desenvolvimento do mesmo, 
trazendo benefícios para os agentes envolvidos e para a sociedade.

\section{REFERÊNCIAS}

AAKER, D. A.; KUMAR, V.; DAY, G. S. Pesquisa de marketing. São Paulo: Atlas, 2004.

ASSIS, O.B.G. 0 uso de vidro reciclado na confecção de membranas para microfiltração. Cerâmica, v. 52, n. 32, p. 105-113, 2006.

BRITO, M; DEKKER, R. A framework for reverse logistics. ERIM Report Series Research In Management, n.. ERS-2003-045-LIS, Erasmus Research Institute of Management (ERIM), 2003.

BYRNE, P.M. and DEEB, A. Logistics must meet the 'green' challenge, Transportation \& Distribution, V. 34, n. 2, p. 33-7, 1993.

CARTER, C.R. and ELLRAM, L.M. Reverse logistics: a review of the literature and framework for future investigation, Journal of Business Logistics, v. 19, n. 1, p. 85-102,1998.

CÉSAR, A. P.; PAULA, D. A.; KROM, A.; Importância Da Reciclagem Do Vidro. In VIII Encontro Latino Americano de Iniciação Cientifica e IV Encontro Latino Americano de Pós- Graduação - Universidade do Vale do Paraíba, 2004. Anais do VIII Encontro Latino Americano de Iniciação Cientifica e IV Encontro Latino Americano de Pós-Graduação, 2004.

CNI, FINEP. A indústria e a questão tecnológica. Brasília, 2002.

DÊ A MÃO PARA O FUTURO http://www.maoparaofuturo.org.br/noticias_det.php?not=112. Acesso em 03 de jun. de 2008.

DOWLATSHAHI S., A strategic framework for the design and implementation of remanufacturing operations in reverse logistics, International Journal of Production Research v.43. n.16, 34553480, 2005.

FREITAS, H.; MOSCAROLA, J. Da observação à decisão: métodos de pesquisa e de análise quantitativa e qualitativa de dados. RAE-Eletrônica, v. 1, n. 1, 2002.

GIL, A. C. Métodos e técnicas de pesquisa social. São Paulo: Atlas, 2006.

GODOY, A. S. Pesquisa qualitativa: tipos fundamentais. Revista de Administração de Empresas, v. 35, n. 3, p. 20-29, 1995.

GONÇALVES M. E., MARINS F. A. S., Logística Reversa numa Empresa de Laminação de Vidros: um estudo de caso, Gestão \& Produção, v.13, n.3, p.397-410, 2006.

GONZÁLEZ-TORRES P. L., ADENSO-DIAZ B., Reverse logistics practices in the glass sector in Spain and Belgium, Industrial Engineering School, University of Oviedo, Campus de Viesques, E-33024Gijón, Spain, 2006.

GONÇALVES-DIAS, S. L. F.; TEODÓSIO, A. S. S. Reciclagem do PET: desafios e possibilidades. In XXVI Encontro Nacional de Engenharia de Produção, Fortaleza, 2006. Anais do XXVI ENEGEP, 2006.

HIPPEL, E.. The sources of innovation. Cap. 2. Oxford University Press, 1988.

LACERDA, L. Logística reversa: uma visão sobre os conceitos básicos e as práticas operacionais. Rio de Janeiro: COPPEAD/UFRJ, 2002: p.6.

LIMA, J. B. Pesquisa qualitativa e qualidade na produção científica em administração de empresas. In XXIII ENANPAD, Foz do Iguaçu, 1999. Anais do XXIII ENANPAD, 1999.

MALHOTRA, N. K. Introdução à Pesquisa de Marketing. São Paulo: Pearson Prentice Hall, 2005.

MORAN, M. R. Concentração de Poder em cadeias produtivas: um estudo de caso sobre a indústria do vidro float no Brasil. São Paulo: OTB, 2008.

MURPHY, P.; POIST, R. Management of logistical retromovements. Transportation research forum, $\mathrm{v}$. 
29, n. 1, p. 177-184, 1989.

NEVES, J. L. Pesquisa qualitativa - características, usos e possibilidades. Cadernos de Pesquisas em Administração, v. 1, n. 3, p. 01-05, 1996.

PATRÍCIO, Z. M.; PINTO, M. D. S.; BRITO, S. L. E.; COLOSSI, N. Aplicação dos métodos qualitativos na produção de conhecimento: uma realidade particular e desafios coletivos para compreensão do ser humano nas organizações. In XXIII ENANPAD, Foz do Iguaçu, 1999. Anais do XXIII ENANPAD, 1999.

POHLEN, T.; FARRIS, M. Reverse Logistics in Plastics Recycling. International Journal of Physical Distribution and LogisticsManagement, v. 22, n. 7, p. 34-47, 1992.

RLEC - Reverse Logistics Executive Council. Disponível em: <www.rlec.org/index.html>. Acesso em: 20 junho 2008.

POZZEBON, M; FREITAS, H. M. R. Pela aplicabilidade - com um maior rigor científico - dos estudos de caso em sistemas de informação. Revista de Administração Contemporânea, v. 2, n. 2, p. 143-170, 1998.

ROGERS, D. S.; TIBBEN-LEMBKE, R. S. Going Backwards: Reverse Logistics Practice; IL: Reverse Logistics Exectuve Council, 1999.

SCHENINI, P. C. ; SILVA, F. A. da ; CARDOSO, A. C. F. . Estratégias de Enfrentamento dos Desafios SócioAmbientais: Gestão de Resíduos Sólidos Urbanos e Regularização dos Catadores Informais. In: EnAPG 2006 - Encontro de Administração Pública e Governança, 2006, São Paulo. Anais do EnAPG, 2006.

SCHUMPETER, J.A. The Theory of Economic Development: An Inquiry into Profits, Capital, Credit, Interest, and the Business Cycle. Cambridge Mass: Harvard University Press, 1934.

SEGATTO-MENDES, A. P.; MENDES, N. Cooperação tecnológica universidade-empresa para eficiência energética: um estudo de caso. Revista de Administração Contemporânea, Edição especial , p. 53$75,2006$.

VIEIRA, A. C. M. ; RICCI, F. . Cooperativas Populares de Reciclagem e a Articulação entre geração e renda, reciclagem e gestão ambiental.. In: V Simpósio de Execelência em Gestão e Tecnologia, 2008, Resende-RJ. Anais do V SEGET, 2008.

VIEIRA, V. A.; TIBOLA, F. Pesquisa qualitativa em Marketing e suas variações: trilhas para pesquisas futuras. Revista de Administração Contemporânea, v. 9, n. 2, p. 09-33, 2005.

WU, H. and DUNN, S.C. Environmentally responsible logistics systems, International Journal of Physical Distribution \& Logistics Management, V. 25 n. 2, p. 20-39, 1995.

ZEVIZCOVAS, R. Especial Reciclagem: vidro, gestão de resíduos, n. 15, p. 25, 2008. 